\title{
Contribution to Study of Water Sorption by Some Polypeptides and Collagen
}

\author{
Jacques Guillet, Gérard Seytre, Jean-François May, et Georges Vallet \\ Laboratoire de Chimie Macromoléculaire associé au CNRS Université \\ "Claude Bernard" LYON I, 43, Boulevard du 11 Novembre \\ 1918-69621-Villeurbanne-France.
}

(Received April 17, 1974)

\begin{abstract}
A systematical study of the polypeptides-water isotherms allows us to propound some hypotheses on the contribution of amino acids residues to the collagen water isotherm. A complementary wide-line NMR study of poly(L-proline) II has given more informations on the physical state of water sorbed on these biopolymers.

KEY WORDS Water Sorption / Polypeptides / Collagen / Bound

Water / Free Water / NMR /
\end{abstract}

The shape of the proteins and polypeptideswater isotherms led several authors to propound mathematical equations to describe them. Mac Laren and Rowen ${ }^{1}$ published a review of the main used theories which give the sorbed water content vs. relative humidity. These mathematical expressions are in fact based on hypotheses which do not correspond to reality.

In this work, we determined and tried to analyze the collagen-water isotherms by studying some characteristic polypeptides such as polyglycine $^{2}$, poly(L-alanaline), poly(L-proline), poly(L-hydroxyproline), and poly( $\beta$-aspartic acid). A study of the water sorption at different temperatures allows us to calculate the water sorption heat. Wide-line NMR experiments on poly(Lproline) II gave some explanations on the physical state of sorbed water.

\section{EXPERIMENTAL}

Polypeptides were obtained from Miles Yeda Laboratories. We controlled their purities by titrating their elements by microanalysis. We also identified their structure by comparison of their infrared spectra and X-ray diffraction patterns with the literature ones.

The average molecular weight of polyglycine, determined by titration of amino end-groups, is 2200. Polyglycine I presents a $\beta$ structure (planar zig-zag) Polyglycine II, with helical structure, is prepared from form I, by dissolution at room temperature in a saturated lithium bromide solu- tion and by subsequent precipitation in water.

Poly(L-proline) (molecular weight 11800 measured by viscosimetry) presents two structural forms: poly(L-proline) I (right-hand helix with peptide bonds in "cis" configuration) and poly(L-proline) II (left-hand helix with peptide bonds in "trans" configuration).

Form II is obtained by dissolution of form I in redistilled formic acid, ensuing evaporation and acetone washing.

Poly(L-alanine), with helical structure, has a molecular weight of 1670 .

Poly(L-hydroxyproline is lyophilised. Its molecular weight is 16700 Form A has a structure similar to that of poly(L-proline) II. Form B, obtained by evaporation of an aqueous solution of form A, has no well-defined structure, and we can assimilate it to a disordered state.

Poly( $\beta$-aspartic acid), with helical structure, has a molecular weight of 2300 .

The molecular weight of these last three polypeptides were determined by ultracentrifugation.

The collagen we used is calf-skined lyophilised acid-soluble collagen.

The determination of water contents of these samples was realized by the McBain method in an apparatus previously described. ${ }^{2}$

\section{EXPERIMENTAL RESULTS}

Sorption water isotherms at different temperatures are represented on Figure 1. The curves are second-type isotherms, similar to those ob- 
Water Sorption by Polypeptides and Collagen

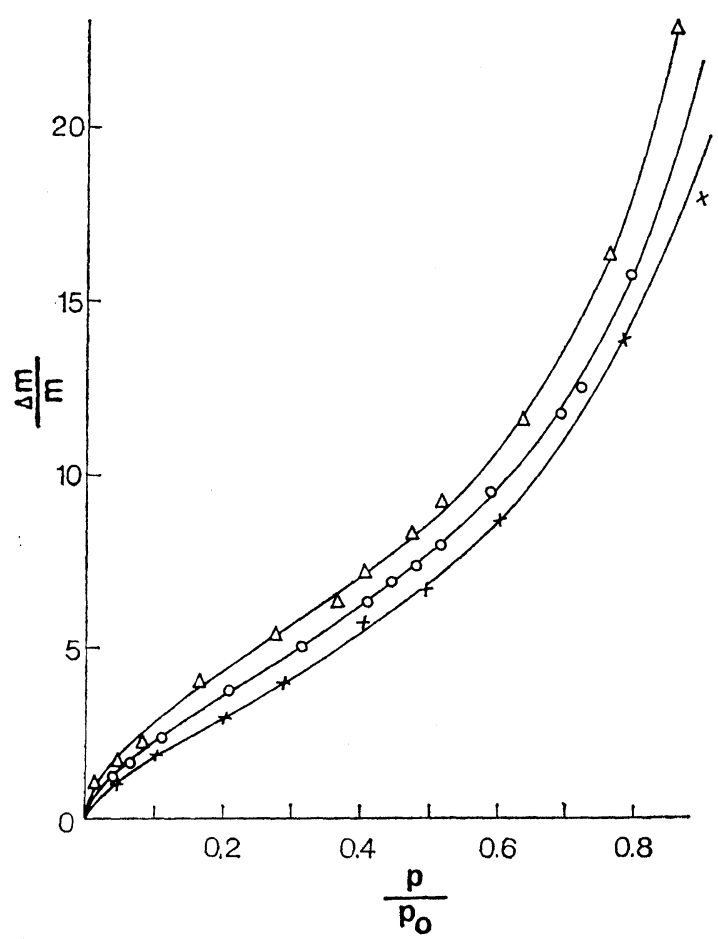

1(a). Poly(L-alanine): $\triangle, 30^{\circ} \mathrm{C} ; \bigcirc, 40^{\circ} \mathrm{C} ; \times, 50^{\circ} \mathrm{C}$.

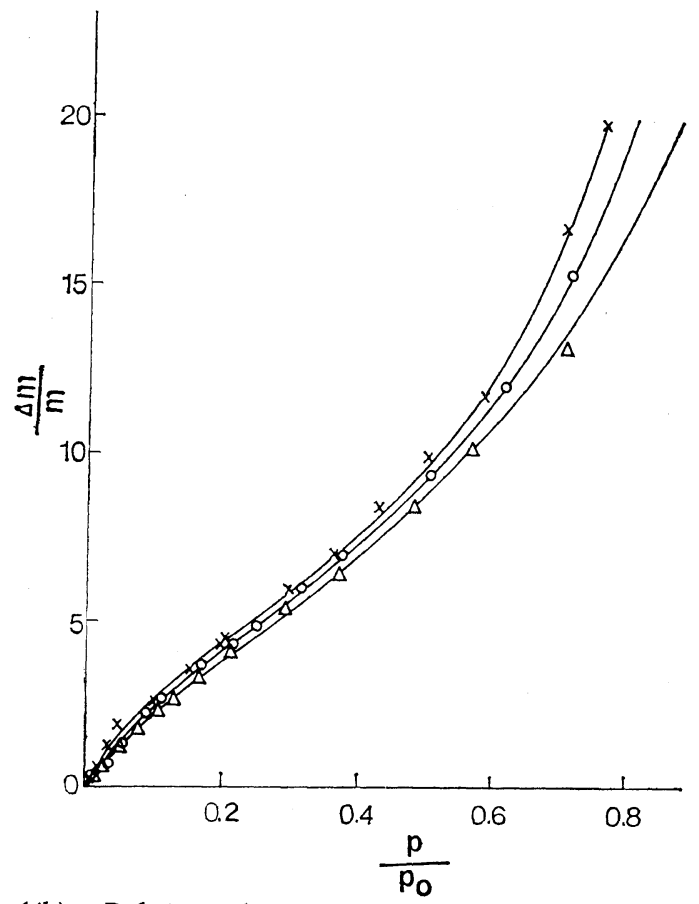

1(b). Poly(L-proline) II: $\quad \times, 35^{\circ} \mathrm{C} ; \bigcirc, 42.5^{\circ} \mathrm{C} ; \triangle$ $50.5^{\circ} \mathrm{C}$.

Polymer J., Vol. 7, No. 1, 1975



1(c). Poly(L-hydroxyproline): $O$, form $\mathrm{A}$ at $30^{\circ} \mathrm{C}$; $\triangle$, form $B$ at $30^{\circ} \mathrm{C} ; x$, form $\mathrm{B}$ at $40^{\circ} \mathrm{C} ; \square$, form $\mathrm{B}$ at $50^{\circ} \mathrm{C}$.

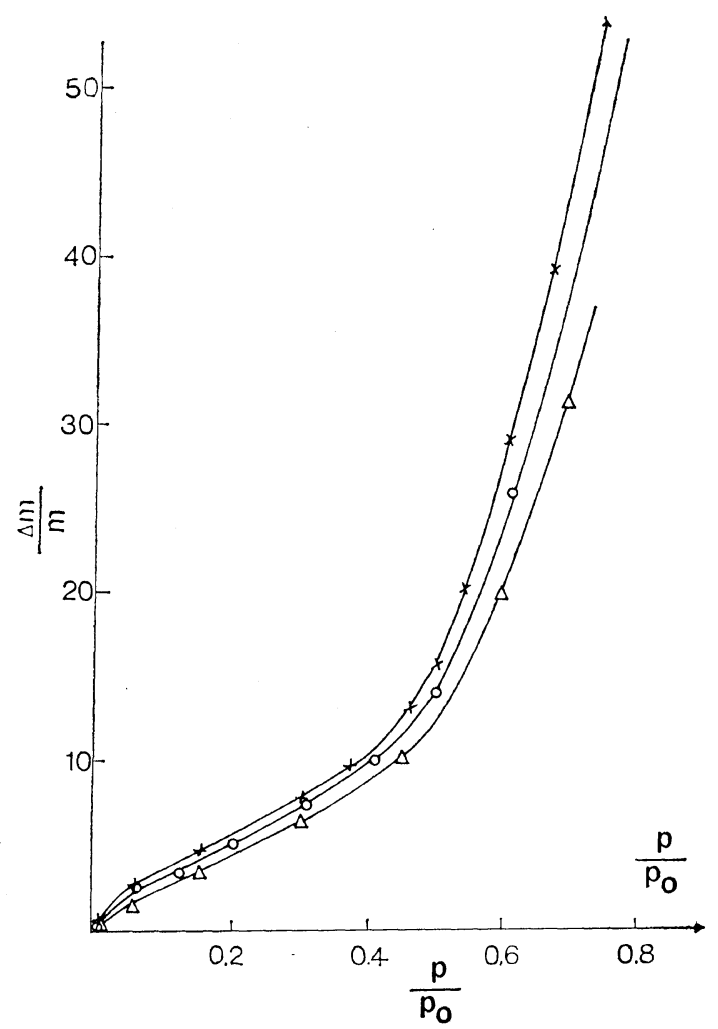

1(d). Poly $\left(\beta\right.$-aspartic acid): $\times, 30^{\circ} \mathrm{C} ; \bigcirc, 40^{\circ} \mathrm{C} ; \triangle$, $50^{\circ} \mathrm{C}$. 


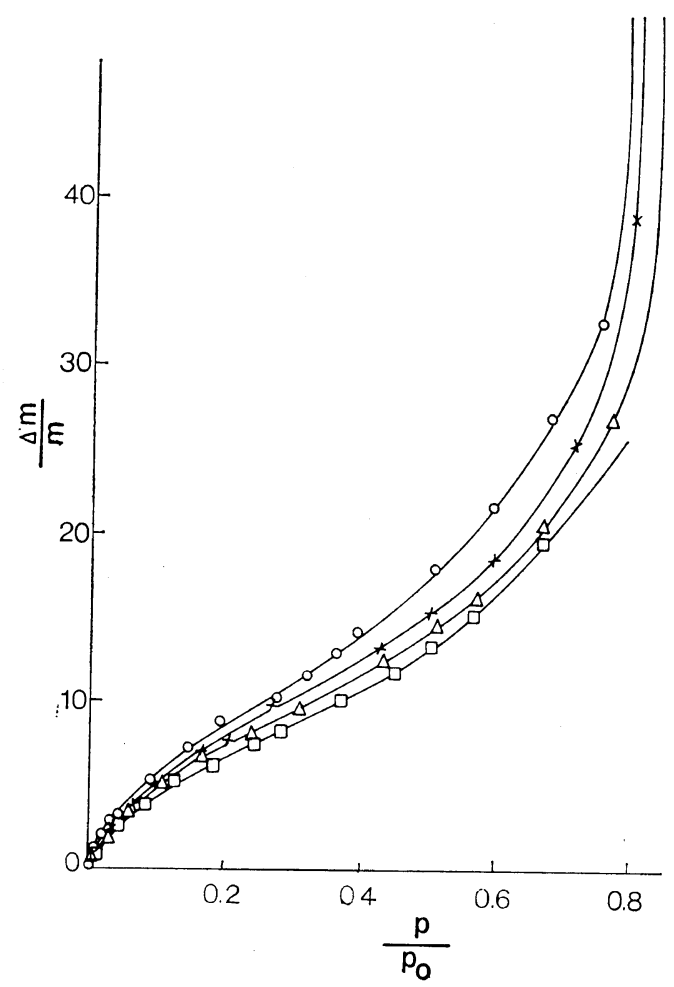

1(e). Collagen: $\bigcirc, 20^{\circ} \mathrm{C} ; \times, 30^{\circ} \mathrm{C} ; \triangle, 40^{\circ} \mathrm{C} ; \square$, $50^{\circ} \mathrm{C}$.

Figure 1. Water sorption isotherms of different polypeptides and collagen.

tained for most of the proteins. Figure 2 recapitulates the isotherms of each studied products at $30^{\circ} \mathrm{C}$. We can see that the compounds having polar side chains (collagen, polyhydroxyproline A and $\operatorname{poly}(\beta$-aspartic acid)) fix much more water than other polypeptides. Although sorption preferentially occurs on definite sites, the linear transformations of the Bet's equation are straight lines for relative humidities $P / P_{0}$ inferior or equal to 0.5 .

The form of the equation of S. Brunauer, P. E Emmet and E. Teller is:

$$
\frac{h}{r(1-h)}=\frac{1}{r_{0} C}+\frac{(C-1) h}{r_{0} C}
$$

in which

$h=P / P_{0}$ is relative humidity

$r_{0}=$ percentage of water sorbed as a monolayer at constant temperature

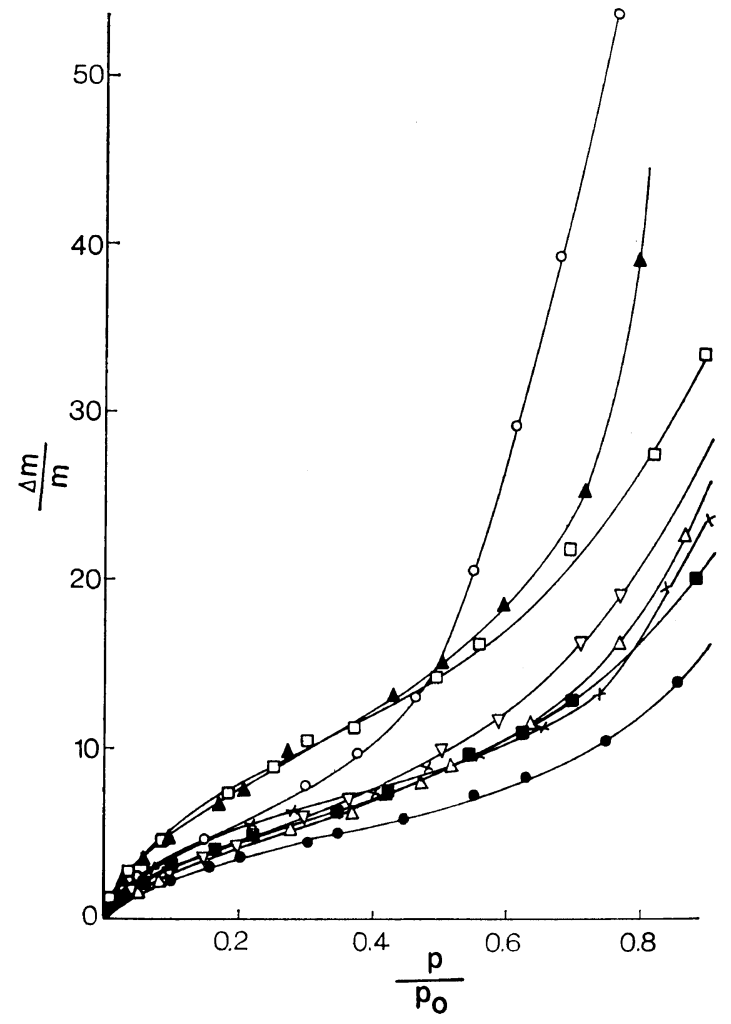

Figure 2. Water sorption isotherms of polypeptides and collagen at $30^{\circ} \mathrm{C}$. Isotherms of poly(L-proline) II is at temperature $35^{\circ} \mathrm{C}: \Delta$, collagen; $\square$, poly(L-hydroxyproline) A; $\bigcirc$, poly $(\beta$-aspartic acid); $\nabla$, poly(L-proline) II; $\triangle$, poly(L-alanine); $\times$, poly $(\mathrm{L}-$ hydroxyproline) B; $\square$, polyglycine II; $\boldsymbol{O}$, polyglycine $\mathrm{I}$.

$r=$ percentage of sorbed water for pressure $P$ at constant temperature

$C=$ Bet constant

$r$ and $r_{0}$ are expressed in terms of $\mathrm{g}$ of water per $100 \mathrm{~g}$ of dry product.

The values of $r_{0}$ at different temperatures are indicated in Table I.

Using the Clapeyron's equation:

$$
\frac{\mathrm{d} \log P}{\mathrm{~d}(1 / T)}=-\frac{\Delta H}{R}
$$

where

$P$ is the water vapor pressure

$T$ the temperature in Kelvin we calculated the sorption heat $\Delta H$ for different water contents. The all results for studied polypeptides and collagen are represented on Figure 3. 
Water Sorption by Polypeptides and Collagen

Table I. a

\begin{tabular}{lcccccc}
\hline \multicolumn{1}{c}{ Polypeptide } & Molecular weight & $r_{0}$ at $30^{\circ} \mathrm{C}$ & $r_{0}$ at $40^{\circ} \mathrm{C}$ & $r_{0}$ at $50^{\circ} \mathrm{C}$ & $T$ & $R$ \\
\hline Polyglycine $\mathrm{I}^{2}$ & 2200 & $3.4 \%$ & $3.2 \%$ & $3.1 \%$ & - & 0.11 \\
Polyglycine $\mathrm{II}^{2}$ & 2200 & $4.6 \%$ & $4.3 \%$ & $4.1 \%$ & 335 & 0.15 \\
Poly(L-alanine) & 1670 & $5 \%$ & $4.5 \%$ & $4.3 \%$ & 108 & 0.2 \\
Polyproline $\mathrm{II}^{\mathrm{b}}$ & 11800 & $6.6 \%$ & $5.8 \%$ & $5.4 \%$ & 120 & 0.322 \\
Polyproline II & 3050 & $8.7 \%$ & - & - & - & - \\
Polyhydroxyproline A & 16700 & $9.4 \%$ & - & - & 93.6 & 0.47 \\
Polyhydroxyproline B & 16700 & $5.6 \%$ & $4.7 \%$ & $4.5 \%$ & - & 0.33 \\
Poly( $\beta$-aspartic acid) & 2300 & $8 \%$ & $7.9 \%$ & $7.7 \%$ & 49 & 0.51 \\
Collagen & $\simeq 30000$ & $8.4 \%$ & $7.8 \%$ & $7.4 \%$ & 1000 & - \\
\hline
\end{tabular}

a $r_{0}$, water content sorbed as a "monolayer" (in $\mathrm{g}$ per $100 \mathrm{~g}$ of dry product); $T$, number of amino-acid residues per 1000 residues of collagen; $R$, number of sorbed water molecules as a monolayer for one

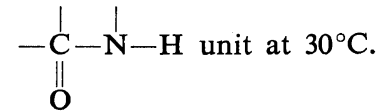

b $r_{0}$ value at $30^{\circ} \mathrm{C}$ was calculated using Clapeyron's equation; at $35^{\circ} \mathrm{C}, r_{0}=6 \%$ for this sample.

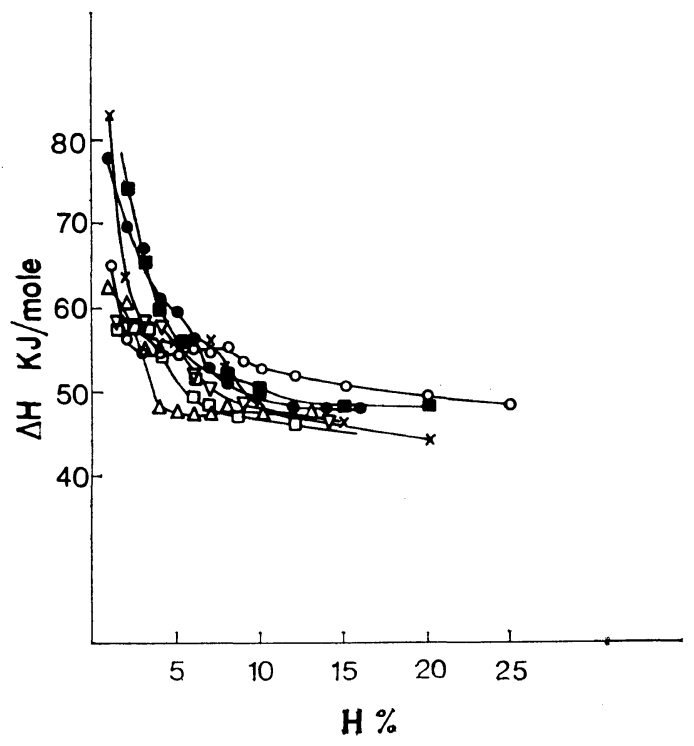

Figure 3. Variations of isosteric heats $v s$. water content (in $\mathrm{g}$ per $100 \mathrm{~g}$ of dry product): $\times$, poly(L-hydroxyproline) B; $\mathbf{O}$, poly(L-alanine); $\mathbf{\square}$, poly( $\beta$-aspartic acid); $\bigcirc$, collagen; $\triangle$, poly(L-proline) II; $\nabla$, polyglycine II; $\square$, polyglycine I.

It stands to reason that the first sorbed water molecules are very strongly bound. Sorption heats then become steady until a water content corresponding to the monolayer saturation and then rearch up to a constant value in the vicinity of the water condensation heat $(44 \mathrm{~kJ} / \mathrm{mol})$. Our results on collagen are in agreement with
Bull $^{4}$ and Kanagy's ${ }^{5}$ ones. On the other hand, the obtained values for poly(L-proline) II and poly(L-hydroxyproline) A are very different from those found by Baskhara, et al. ${ }^{6}$ These authors estimated at $1.6 \%$ the sorbed water content as a monolayer on poly(L-proline) II at $40^{\circ} \mathrm{C}$. This value seems rather small as regards the electric behaviour of hydrated poly(L-proline) II. $^{7}$

Hailwood and Horrobin's theory, founded on hypotheses different from the Bet ones, allows to calculate apart free and bound water contents retained by the product. These authors assume the existence of a water-protein complex, in equilibrium with the remainder of water retained by the protein. They aknowledge that the system constituted with free water, hydrate and groups able to fix one molecule of water, makes a solidsolution enough ideal to substitute for activities the concentration in equilibrium with the vapor phase.

They obtain so the relation:

$$
\frac{M r}{1800}=\frac{\alpha h}{1-\alpha h}+\frac{\alpha \beta h}{1+\alpha \beta h}
$$

$M=$ weight of polymer able to fix one molecule water "as hydrate"

$r=$ percentage of sorbed water in $\mathrm{g}$ per $100 \mathrm{~g}$ of dry product

$\alpha=$ constant of the equilibrium: vaporized water $\rightleftarrows$ free water

$\beta=$ constant of the equilibrium: hydrate $\rightleftarrows$ mass of accessible polymer + free water 
$h=P / P_{0} \times 100$ : percentage of relative humidity. This relation can be written also:

$$
A+B h-C h^{2}=\frac{h}{r}
$$

with

$$
\begin{aligned}
& A=\frac{M}{1800(1+\beta) \alpha}, \quad B=\frac{M(\beta-1)}{1800(1+\beta)}, \\
& C=\frac{\alpha \beta M}{1800(1+\beta)}
\end{aligned}
$$

By taking a series of points on the experi-

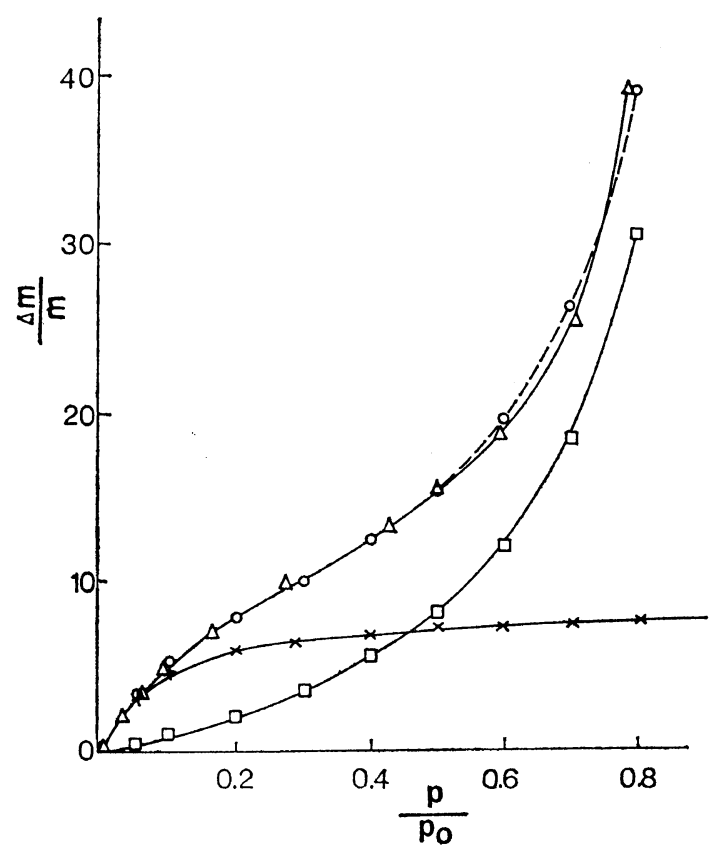

Figure 4. Decomposition of Hailwood and Horrobin on water sorption isotherm of collagen at $30^{\circ} \mathrm{C}: \triangle$, experimental isotherm; $O$, theoretical isotherm; $\square$, free water; $x$, bound water. mental isotherm, we can so obtain a system of several equations which lead to A, B, C coefficients.

We may so calculate the quantities of free water $r_{1}$ and bound water $r_{2}$ retained by the protein. The sum is evidently equal to the total sorbed water $r$.

$$
r_{1}=\frac{\alpha h}{1-\alpha h} \frac{1800}{M} \quad \text { and } \quad r_{2}=\frac{\alpha \beta h}{1+\alpha \beta h} \frac{1800}{M}
$$

An example of decomposition of the collagen

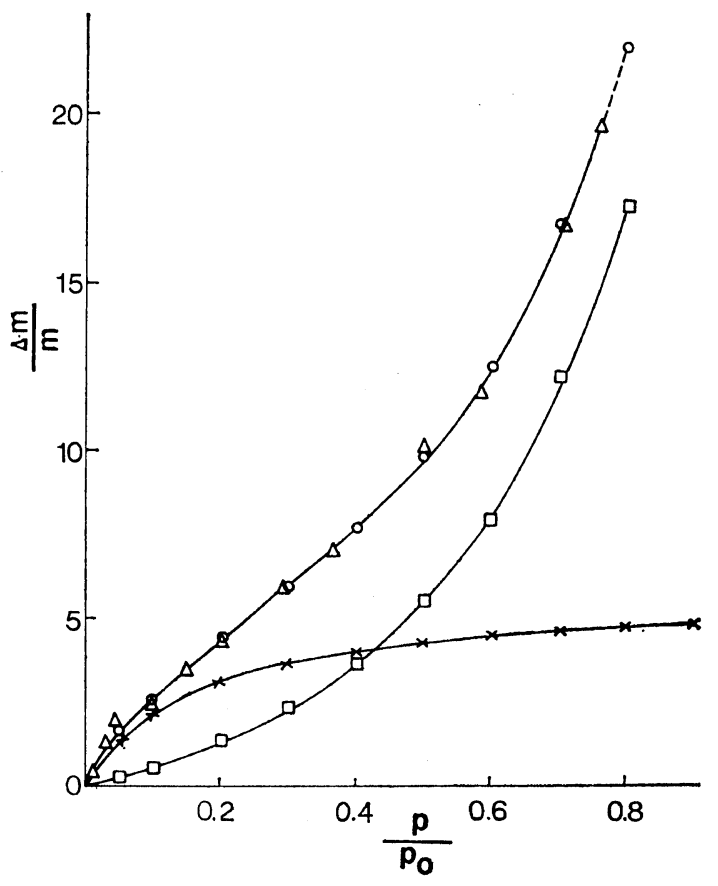

Figure 5. Decomposition of Hailwood and Horrobin on water sorption isotherm of poly(L-proline)

\begin{tabular}{|c|c|c|c|c|c|}
\hline Polypeptides & A & B & $\mathrm{C}$ & $\begin{array}{c}M^{\text {a }} \text { at } 30^{\circ} \mathrm{C} \\
\text { (B.E.T.) }\end{array}$ & $\begin{array}{c}M^{\mathrm{a}} \text { at } 30^{\circ} \mathrm{C} \\
\text { (Hailwood and } \\
\text { Horrobin) }\end{array}$ \\
\hline Polyglycine II & 1.56 & 0.182 & $2 \times 10^{-3}$ & $391 \mathrm{~g}$ & $356 \mathrm{~g}$ \\
\hline Poly(L-alanine) & 2.85 & 0.141 & $1.75 \times 10^{-3}$ & $360 \mathrm{~g}$ & $360 \mathrm{~g}$ \\
\hline Poly(L-proline) II $^{\mathrm{b}}$ & 2.6 & 0.122 & $1.42 \times 10^{-3}$ & $305 \mathrm{~g}$ & $310 \mathrm{~g}$ \\
\hline Poly(L-hydroxyproline) A & 1.27 & 0.081 & $7.45 \times 10^{-3}$ & $193 \mathrm{~g}$ & $183 \mathrm{~g}$ \\
\hline Poly( $\beta$-aspartic acid) & 1.43 & 0.12 & $2.31 \times 10^{-3}$ & $230 \mathrm{~g}$ & $340 \mathrm{~g}$ \\
\hline Collagen & 0.962 & 0.1 & $1.08 \times 10^{-3}$ & $214 \mathrm{~g}$ & $214 \mathrm{~g}$ \\
\hline
\end{tabular}
II at $35^{\circ} \mathrm{C}: \triangle$, experimental isotherm; $O$, theoretical isotherm; $\square$, free water; $\times$, bound water.

Table II.

a $M$, weight of polymer able to fix one water molecule as hydrate.

b poly(L-proline) II was studied at $35^{\circ} \mathrm{C}$. 
and polyproline-water isotherms is presented on Figures 4 and 5 .

The values of $\mathrm{A}, \mathrm{B}, \mathrm{C}$ parameters are given in Table II. We may note the very good agreement between $M$ obtained by Hailwood and Horrobin's theory and $M$ obtained by the Bet one. However, there is an anomaly for poly( $\beta$-aspartic acid).

We think that this error is owing to the particular shape of the isotherm, especially at high vapour pressures.

\section{DISCUSSION}

As regards Figures 2 and 3, it seems that water sorption depends on the polypeptide structure and to a large extent, on the reactivity of sidechain polar groups.

If we compare the two structural forms of polyglycine, we see that helical structure retains much more water than the $\beta$ structure. Poly(L-alanine) has a similar behaviour. Poly(L-proline) II, with analogous structure, is of particular interest. We may suppose that the number of interchain hydrogen bonds is rather limited because of the tertiary nitrogen atom. Sites are thus more easily accessible for the first molecules of water, that explains a larger sorption (see Table I).

If we consider now the two forms of poly(L-hydroxyproline), independently of hydroxyl group substituted on the pyrrolidin ring, we see that poly(L-hydroxyproline) A, with helical structure, absorbs much more water than form B which has no clearly defined structure. These experimental results suggest that helical structure facilitates the access of molecules of water on hydrophilic sites.

It is fitting here to specify that molecules of water do not fix themselves only on amino or carboxyl end-groups. Indeed a rough calculation shows an excess of several molecules of water for the different studied polypeptides. It seems logical to think that peptides groups are also responsible of sorption. To value the contribution of end-groups, we did a study of water sorption on poly(L-proline) II with a molecular weight of 3050 . We could so calculate that endgroups retained around five molecules of water, the remainder being distributed on peptid groups, that suppose about one molecule of water for three $-\underset{O}{\mathrm{C}-\mathrm{N}}$ - units (see Table I). We must also point out that the expression "monolayer" is unsuitable. Measurements on powder samples and compressed pastilles, gave results varying by less than $5 \%$.

The difference which justify the comparison of results suggests that sorption is not a function of the surface state. This is confirmed by the high values of isosteric heats. So, the sorbed water content, independent of surface of samples, would rather depend on the "sorption capacity" of polar groups contained in the studied products. More over, we see in Table I that these polar groups are not all occupied by molecules of water.

To study the influence of the side-chain substituents, we may compare both poly(L-proline) II and poly(L-hydroxyproline) A. These two polypeptides are similar from a structural point of view, but poly(L-hydroxyproline) has an hydroxyl group. By difference, we obtain a contribution of hydroxyl groups to the sorption of $0.24 \mathrm{~mol}$ of water per amino acid residue. In the same way, the comparison of poly $(\beta$-aspartic acid) and poly(L-alanine) allows to value the contribution of a side-chain carboxyl group. The calculation gives $0.32 \mathrm{~mol}$ of water per amino acid residue.

The constituting amino acids of our polypeptides represent around $70 \%$ of the composition of collagen, in number of amino acid residues per 100 residues (see Table I). Assuming that water affinity of an amino acid residue of collagen is the same as that of corresponding polyaminoacid, we determined that these amino acids only contributed for $40 \%$ to the total sorption of collagen. This rough calculation lets us imagine the influence of the other collagen amino acids, especially those having amino side-chains. We may think that the role of basis is preponderant in water sorption by collagen.

The physical state of sorbed water is a question that many authors investigated..$^{9,10,11}$ The use of Hailwood and Horrobin's theory for our compounds is of great interest, and in good agreement with Bet's theory. One may note 


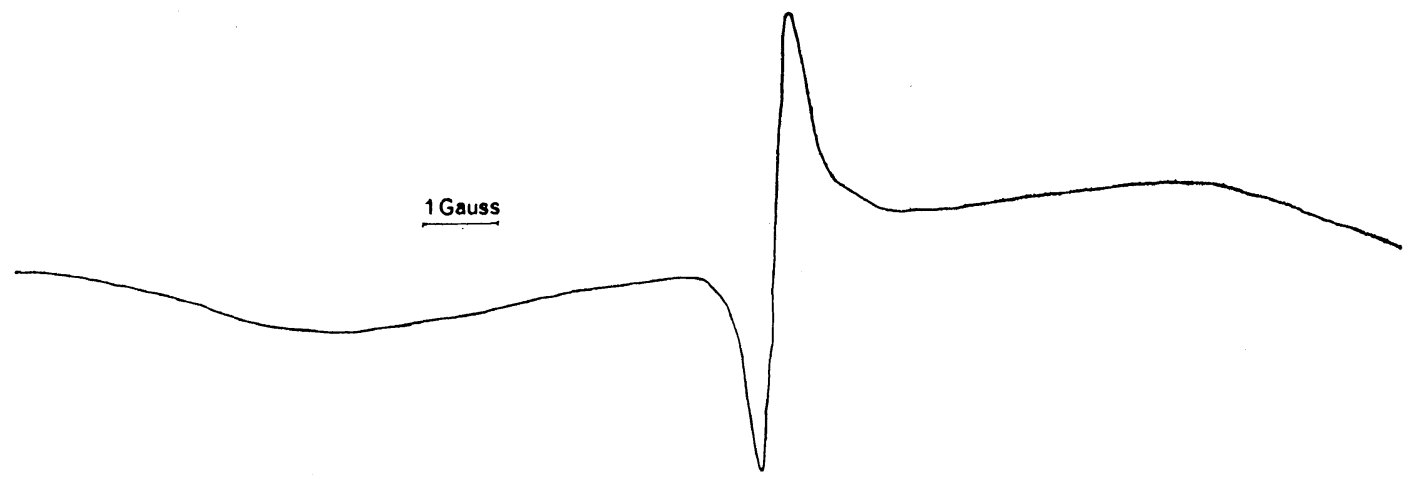

Figure 6. Wide-line NMR spectrum of poly(L-proline) II with $2.3 \%$ of water content: Frequency, $16 \mathrm{MHz}$; modulation amplitude, $0.5 \mathrm{G}$; temperature, $35^{\circ} \mathrm{C}$.

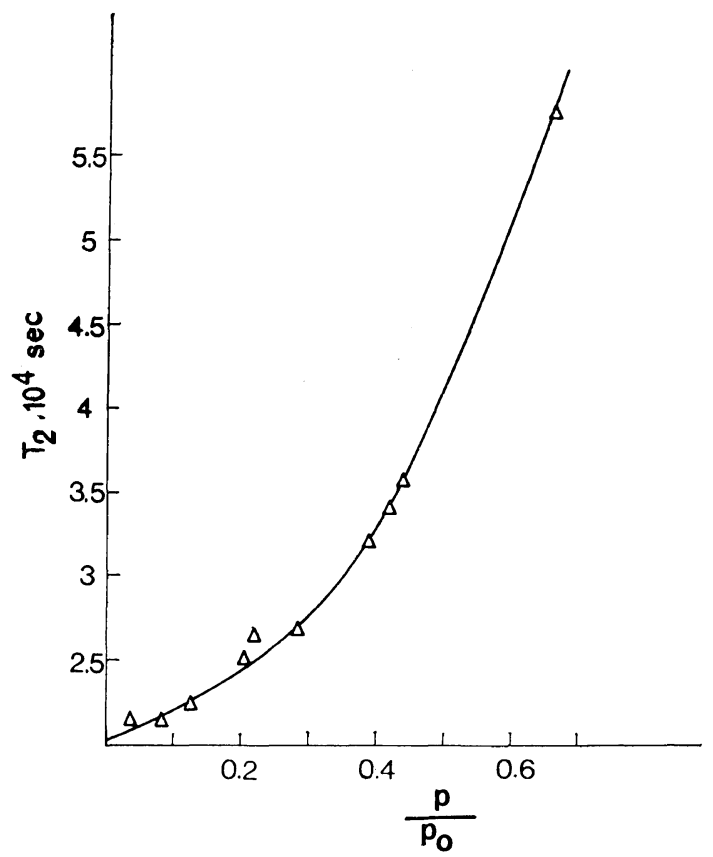

Figure 7. Variation of the spin-spin relaxation time associated to the narrow band $v s$. relative humidity.

that $r_{0}$ values (Bet) and $M$ (Hailwood and Horrobin) values are the ones for which authors generally observe a sharp rise of the dielectric constant of samples. Chang and Chien ${ }^{12}$ remarked a similar phenomena on collagen and we previously describe an analogous behaviour of hydrated poly(L-proline) ${ }^{7}$. The currently acknowledged hypothesis prescribe to distinguish water free or bound to a protein. To elucidate this problem,



Figure 8. Variations of the spin-spin relaxation time associated to the wide band $v s$. relative humidity.

we undertook a wide line NMR study of on these products hydrated in the same conditions as in McBain gravimetric absorption.

NMR experiments were made on a Bruker BKR spectrometer at the frequency of $16 \mathrm{MHz}$.

Figure 6 represents an NMR spectrum of poly(L-proline) II hydrated at $2.3 \%$ at $35^{\circ} \mathrm{C}$. We observe a wide band $(\simeq 11 \mathrm{G})$ probably due to the resonance of protons of polypeptidic chain. We can also notice the presence of a narrow 
band $(150 \mathrm{mG})$ probably associated to the resonance of the free water protons. Lindler and Forslind $^{13}$ obtained two similar bands with hydrated collagen. These authors observed also an intermediary band $(\simeq 500 \mathrm{mG})$ which they attributed to resonance of bound water protons. We could not show off this band in the poly(L-proline) II and we think it is masked by the wide band. As regards the narrow line, we detect it even for very low water contents. This fact suggests that free water is present since the beginning of sorption, in agreement with the with the hypothesis of Hailwood and Horrobin. Figure 7 represents the variations of the spinspin relaxation time associated to the narrow band $v s$. partial pressure of vaporized water. This variation is similar to the free water content $r_{1}$, (see Figures 4 and 5). On Figure 8, the variation of the spin-spin relaxation time associated to the wide band is also comparable to the bound water content $r_{2}$ As we saw previously we must not therefore reasonably attribute this resonance to bound water, but rather to protons of the backbone. Indeed, the relaxation time compared with those obtained from litterature is too little. The relaxation time reaches a constant value as early as water contents arise $5-6 \%$. This value can be compared with $r_{0}$ at $35^{\circ} \mathrm{C}$ calculated by Bet's theory (see Table I). It seems that bound water would facilitate the vibrations of protons of the polypeptidic chain. A more detailed study is in progress to elucidate these particular points.

\section{CONCLUSION}

Water sorption of polypeptides led us to consider the influence of structure and of side chains polar groups. We thus determined the contri- bution to the sorption of hydroxyl and acid carboxyl groups. It would be interesting to know the influence of amino group, to quantitatively analyze the water collagen isotherm. On an other way, wide-line NMR proved the presence of free water at the beginning of sorption. This experimental result justifies the employment of Hailwood and Horrobin's theory. A more systematical study would allow us to investigate sorption mechanisms. We could so undertake an easier theoretical approach of charge-transfer mechanisms inside biological substances set in an electrical fields. ${ }^{2-7}$

\section{REFERENCES}

1. A. D. McLaren and J.W. Rowen, J. Polym. Sci., 7, 289 (1951).

2. G. Seytre, J. F. May, and G. Vallet, J. Chim. Phys., 6, 959 (1972).

3. V. Sasisekharan, J. Polym. Sci., 47, 391 (1960).

4. H. B. Bull, J. Amer. Chem. Soc., 66, 1499 (1944).

5. J. R. Kanagy, J. Res. Natl. Bur. Std., 44, 31 (1950).

6. P. Bhaskara Rao and L. M. Yeddanapalli, Leather Sci., 17, 349 (1970).

7. J. Guillet, G. Seytre, J. F. May, and G. Vallet, Die Makrom. Chem., 172, 199 (1973).

8. A. J. Hailwood and S. Horrobin, Trans. Faraday Soc., 42B, 84 (1946).

9. G. E. Chapman, S. S. Danyluk, and K. A. Lauchlan, Proc. Roy. Soc. (London), 178, 465, (1971).

10. D. T. Warner, Reprints from Ann. Rep. in Medic. Chem., 23, 256 (1969).

11. A. Frommer and D. Lancet, J. Appl. Polym. Sci., 15, 1295 (1972).

12. E. P. Chang and J.C.W. Chien, J. Polym. Sci., 11, 737 (1973).

13. P. Lindler and E. Forslind, Chemica Scripta, 3, 57 (1973). 